\title{
Characteristics of Ship Movements in a Fairway
}

\author{
Eun Kyung Kim, Jung Sik Jeong*, Gyei-Kark Park, Nam Kyun Im \\ ${ }^{1}$ Department of Maritime Transportation system, \\ Mokpo National Maritime University, Mokpo, Jeonnam, 530-729, Korea
}

\begin{abstract}
In a coastal area, all of the vessels are always exposed to the potential risk, taking into the maritime accident statistics account over the last decades. To manage vessels underway safety, the characteristics of ship movements in a fairway should be recognized by VTS system or VTS operators. The IMO has already mandated the shipboard carriage of AIS since 2004, as stated in SOLAS Chapter V Regulation 19. As a result, the static and dynamic information of AIS data has been collected for vessel traffic management in the coastal areas and used for VTS. This research proposes a simple algorithm of recognizing potentially risky ships by observing their trajectories on the fairway. The static and dynamic information of AIS data are collected and the curvature for the ship trajectory is surveyed. The proposed algorithm finds out the irregularity of ship movement. The algorithm effectively monitors the change of navigation pattern from the curvature analysis of ship trajectory. Our method improves VTS functions in an intelligent way by analyzing the navigation pattern of vessels underway.
\end{abstract}

Keywords : AIS data, Navigation pattern, Ship movement, Ship trajectory monitoring, Maritime safety management, VTS.

\section{Introduction}

The increase of shipping has brought from the congestion of the maritime traffic, which also increases the potential risk for the maritime accident. The effective management of ship movements in a waterway is essential to reduce the rate of maritime accidents. Many researchers have been carried out to improve the maritime safety through the vessel CPA analysis and anti-collision control system [1][2].

The IMO has mandated the shipboard carriage of AIS since 2004, as stated in SOLAS Chapter V Regulation 19. As a result, the static and dynamic information of AIS data has been collected for vessel traffic management in the coastal areas and used for VTS[3][4]. Recently, e-Navigation strategic plan emphasizes the role of shore facilities to enhance the safety of navigation. It is expected that AIS data can be effectively utilized to support VTS and to manage the ship safety, taking into various information of ship movement account.

By using AIS data, the navigation pattern in time domain on a fairway can be analyzed. Several researches of building the effective safety system have been reported [5][6].

According to the accidents statistics in Korean coastal areas, the marine accident has been increased continuously over the last 5 years. The reason is that a lot of marine accidents by the human factor like the carelessness of navigator. The abnormal sailing ship having potential high risk may threaten normal voyage vessels on route.

There is a research on the abnormality vessel identification system utilizing the existing fuzzy logic. It is difficult to recognize traffic condition and pattern change only visually[7].

Manuscript received Nov. 30, 2012; revised Dec. 15, 2012; accepted Dec. 18. 2012

* Corresponding author: Jung Sik Jeong (jsjeong@mmu.ac.kr)

(c) The Korean Institute of Intelligent Systems. All rights reserved.
This research proposes a simple algorithm of recognizing the potentially risky ships by observing their trajectories on the fairway. The static and dynamic information of AIS data are collected and the curvature of ship trajectory is surveyed. The proposed algorithm finds out the irregularity of the ship movement. The algorithm effectively monitors the change of navigation pattern from the curvature analysis of ship trajectory. If the system notices the irregularity of ship movement and warns navigator, it will contribute to the safety of navigation on fairway. Our method improves VTS functions in an intelligent way by analyzing the navigation pattern of vessels underway.

\section{Method of Study}

\subsection{AIS messaging information}

AIS data divides into the static, dynamic data for the efficient treatment of data. The AIS data has the three types of information which includes static data, variable information, dynamic information. And the AIS data also has the message for the weather or the safe navigation etc.

The content of static data is IMO number, signal letters and ships name, length and beam, form of the vessel, vessel's position by GPS, dangerous freight, destination port, estimated time of arrival, route plan etc.

The dynamic information is the external sensor, providing the location (the accuracy and the condition) of the vessel, UTC time, heading line, ground speed, azimuth, pilotable angle speed, angle of heel, pitching and rolling, additional information etc. And the safe related message includes represents meteorological messages soon[8].

Table 1 is the type of each AIS messaging information. 
Table 1. Type of AIS message

\begin{tabular}{|c|l|}
\hline Message ID & \multicolumn{1}{|c|}{ Description } \\
\hline $1,2,3$ & Position -Scheduled \& Special position report \\
\hline 4 & Contains position, UTC, date and slot number \\
\hline 5 & Static and voyage related data \\
\hline $6,7,8$ & Binary message to mobile or fixed station \\
\hline 9 & Periodical alternate message \\
\hline 10,11 & UTC/Date inquiry \\
\hline $12,13,14$ & Safety related point to point message \\
\hline 15 & Request for a specific message type \\
\hline 16 & Assignment of a specific report behavior \\
\hline 17 & Differential corrections \\
\hline 18.19 & Third source target input \\
\hline 20 & Data link management \\
\hline 21 & Proprietary data \\
\hline 22 & Channel assignment \\
\hline
\end{tabular}

In this research, the real time implementation object message used no. 1, 2, 3 and no. 5 of AIS. The message No. 1, 2, 3 presents ship position in UTC. It utilized for the vessel resistance analysis through the location of ship and speed of the vessel.

\subsection{Curvature $k$ for ship trajectory}

In this paper, the curvature equation is used in order to analyze the curvature of the trajectory of the vessel. The curvature $k$ of vessel trajectory can be calculated from ship's position in ship's position as a function of time.

$$
\begin{aligned}
k & =\frac{d \phi}{d s}=\frac{d \phi / d t}{d s / d t} \\
k & =\frac{d \phi / d t}{\sqrt{(d x / d t)^{2}+(d y / d t)^{2}}} \\
& =\frac{d \phi / d t}{\sqrt{\dot{x}^{2}+\dot{y}^{2}}}
\end{aligned}
$$

The need for $d \phi / d t$ can be eliminated by the following identity:

$$
\begin{aligned}
& \tan \phi=\frac{d y}{d x}=\frac{d y / d t}{d x / d t} \\
& \frac{d \phi}{d t}=\frac{1}{1+\tan \phi^{2}} \cdot \frac{\dot{x} \ddot{y}-\dot{y} \ddot{x}}{x^{2}}
\end{aligned}
$$

Substituting Eq. (4) into Eq. (3), Eq. (5) gives the final expression for the curvature calculated from the $x$ and $y$ time domain signals :

$$
k=\frac{\dot{x} \ddot{y}-\dot{y} \ddot{x}}{\left(\dot{x}^{2}+\dot{y}^{2}\right)^{3 / 2}}
$$

\section{Computer of Simulation}

\subsection{Monte Carlo computer simulation}

This research used the Monte Carlo simulation in order to find out the characteristic of ship movement in a straight fairway.

First, the standard heading angle is designated as 45 degree. The heading angle is arbitrarily assigner. It has normal distribution with variance of 2 degree and 5 degree. At this time, ship speed is unchanged and it is fixed as $v_{1}, v_{2}$. And it appoints the initial position arbitrarily. Table 2 shows simulation condition.

Table 2. The simulation value condition

\begin{tabular}{|l|c|c|c|c|}
\hline & $\begin{array}{c}\text { Ship's } \\
\text { Heading }\left({ }^{\circ}\right)\end{array}$ & $\begin{array}{c}\text { Variance } \\
\left({ }^{\circ}\right)\end{array}$ & $\begin{array}{c}\text { Speed } \\
(\mathrm{m} / \mathrm{sec})\end{array}$ & $\begin{array}{c}\text { Initial position } \\
(\text { Lat, Long) }\end{array}$ \\
\hline Ship 1 & $\phi_{1}$ & 2.0 & $v_{1}=4$ & $\mathrm{~S}_{0}\left(\mathrm{x} 1_{0}, \mathrm{y} 1_{0}\right)$ \\
\hline Ship 2 & $\phi_{2}$ & 5.0 & $v_{2}=4$ & $\mathrm{~S}_{0}\left(\mathrm{x} 2_{0}, \mathrm{y} 2_{0}\right)$ \\
\hline
\end{tabular}

By using the designated value of Table 2, the location of the vessel as a function of time can be found through the Eq. (6).

$$
\begin{aligned}
& \operatorname{ship}_{1}\left\{\begin{array}{l}
x_{1}=x_{10}+v_{1} \cdot \sin \left(\phi_{1}\right) \cdot t s \\
y_{1}=y_{10}+v_{1} \cdot \cos \left(\phi_{1}\right) \cdot t s
\end{array}\right. \\
& \operatorname{ship}_{2}\left\{\begin{array}{l}
x_{2}=x_{20}+v_{2} \cdot \sin \left(\phi_{2}\right) \cdot t s \\
y_{2}=y_{20}+v_{2} \cdot \cos \left(\phi_{2}\right) \cdot t s
\end{array}\right.
\end{aligned}
$$

The sampled positions have the time interval of $20 \mathrm{~s}$.

Figure 1 show the location of the vessel which are obtained through the Eq. (6) to the coordinate system around 45 drawing normal resistance. The trajectory of the real vessel implemented with the soft curve passing by the angular positions through the spline interpolation.

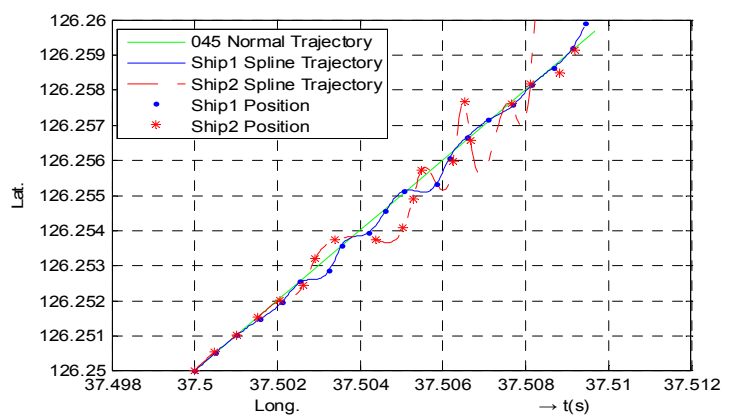

Figure 1. Result of the computer simulation of the vessel trajectory 
In Figure 1, the latitude is plotted along the $\mathrm{X}$ axis, the longitude is plotted along the $\mathrm{Y}$ axis. The polynomial curve fit was computed using MATLAB's POLYFIT function using the result of the simulation. We used the curvature equation to calculate the interpolated trajectory and simulated the result of the curvature value, as shown in Figure 2.

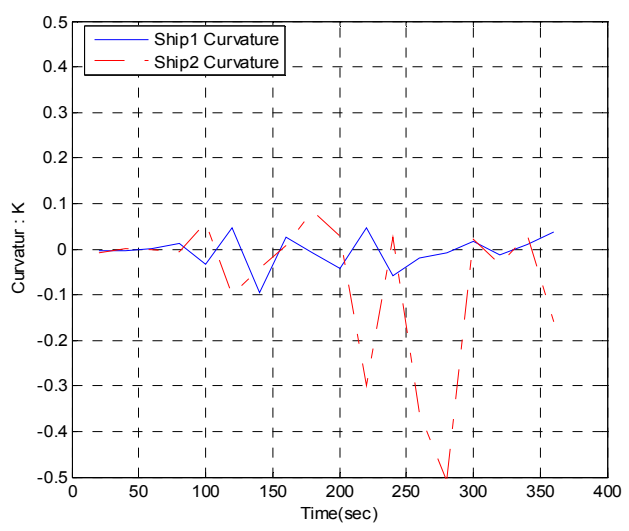

Figure 2. The change of the curvature according to the time evolution.

In figure 2, the time is plotted along the $\mathrm{X}$ axis, the curvature is plotted along the $\mathrm{Y}$ axis. It is shown the change of the curvature according to time in the straight fairway. Comparing the curvature value of 2 vessels, it is seen that the bigger deviation with the standard heading angle by the more zigzag movement, the bigger curvature value of vessel in the straight fairway. Through the simulations, we find the ship with large curvature which has irregularity of the ship movement. We know that the curvature can be used to recognize the characteristics of ship movement in a fairway.

\subsection{The result of simulation by AIS data utilization analysis}

In this research, we collect the read time AIS data of ships from real AIS Wando. This data includes the static of AIS data and dynamic data. The ship trajectories are simulated with realtime AIS data, as shown in Figure 3.

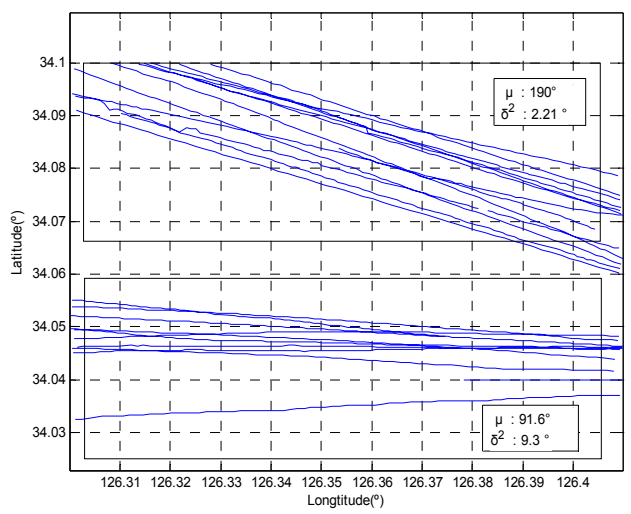

Figure 3. Simulation of Vessel Trajectory distribution at 2012 in Wando waterway by AIS Data.
In Figure 3, the latitude is plotted along the $\mathrm{X}$ axis, the longitude is plotted along the $\mathrm{Y}$ axis. The value of ship's average and its variance are $2.2^{\circ}$ and $9.3^{\circ}$, respectively. Figure 4 shows the trajectory of ship with the variance $18.5^{\circ}$.

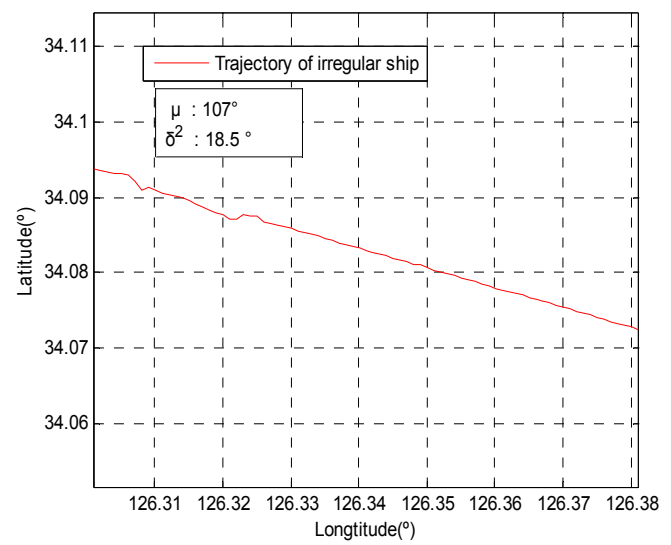

Figure 4. Result of simulation the irregular ship trajectory .

The irregular vessel's average course is 107 degree.

We used the curvature equation to calculate the interpolated trajectory and simulated the result of the curvature value. This result is shown in figure 5 .

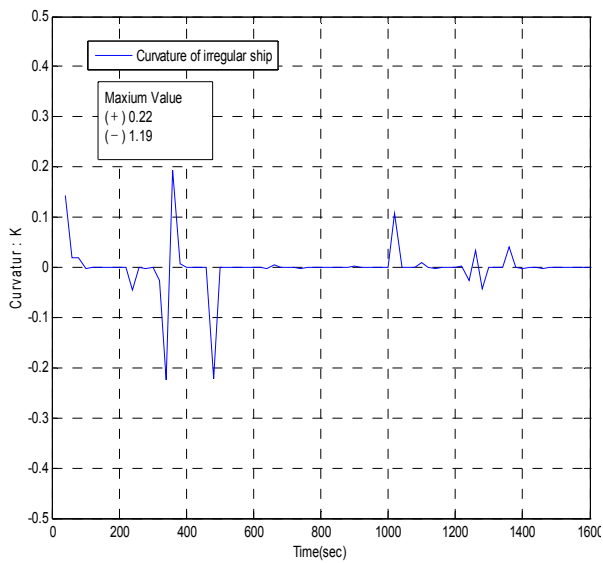

Figure 5. The change of the curvature of irregular ship.

The curvature value change is not worse than the result of computer simulation. However, actual data simulation knows that value of the curvature changes about straight line route. We know that it become one element in which about change of the trajectory and curvature analyze the motion of the vessel through the result of simulation.

\subsection{Marine Accident Case Analysis}

This study analyzed the ship collision between M/V Golden Rose and M/V Jinseong in 2007. Table 3 is the AIS data of Golden Rose and Table 4 is the AIS data of Jinseong. Result of two vessel's trajectory is shown in figure 6 . 
Table 3. AIS data of Golden Rose

\begin{tabular}{|c|c|c|c||c|c|c|c|}
\hline No & $\begin{array}{c}\text { Lat. } \\
38^{\circ} 14^{\prime} \mathrm{N}\end{array}$ & $\begin{array}{c}\text { Long. } \\
121^{\circ} 42^{\prime} \mathrm{E}\end{array}$ & Co. & No & $\begin{array}{c}\text { Lat. } \\
38^{\circ} 14^{\prime} \mathrm{N}\end{array}$ & $\begin{array}{c}\text { Long. } \\
121^{\circ} 42^{\prime} \mathrm{E}\end{array}$ & Co. \\
\hline 1 & 48.6 & 9.6 & 177 & 18 & 27 & 10.7 & 197 \\
\hline 2 & 47.8 & 9.8 & 177 & 19 & 25.8 & 10.2 & 203 \\
\hline 3 & 47 & 10 & 177 & 20 & 25.4 & 9.6 & 211 \\
\hline 4 & 46.2 & 10.2 & 177 & 21 & 25.2 & 9 & 220 \\
\hline 5 & 45.4 & 10.4 & 177 & 22 & 25 & 7.8 & 240 \\
\hline 6 & 44.6 & 10.6 & 177 & 23 & 24.8 & 6.6 & 256 \\
\hline 7 & 43.8 & 10.8 & 177 & 24 & 24.6 & 6 & 259 \\
\hline 8 & 42 & 11 & 177 & 25 & 24.65 & 5.4 & 260 \\
\hline 9 & 40.2 & 11.2 & 177 & 26 & 24.6 & 4.8 & 262 \\
\hline 10 & 37.2 & 11.4 & 176 & 27 & 24.65 & 4.4 & 263 \\
\hline 11 & 32.4 & 12.1 & 177 & 28 & 24.6 & 3.6 & 268 \\
\hline 12 & 31.8 & 12 & 179 & 29 & 24.4 & 3.2 & 269 \\
\hline 13 & 30.6 & 11.42 & 182 & 30 & 25.2 & 2.4 & 279 \\
\hline 14 & 29.4 & 11.3 & 184 & 31 & 25.25 & 1.2 & 288 \\
\hline 15 & 28.2 & 11.2 & 188 & 32 & 25.8 & 0.7 & 299 \\
\hline 16 & 27.6 & 10.9 & 189 & 33 & 26.4 & 0.6 & 307 \\
\hline 17 & 27.4 & 10.81 & 194 & 34 & 26.45 & 0.3 & 311 \\
\hline
\end{tabular}

Table 4. AIS data of Jinseong

\begin{tabular}{|c|c|c|c||c|c|c|c|}
\hline No & $\begin{array}{c}\text { Lat. } \\
38^{\circ} 14^{\prime} \mathrm{N}\end{array}$ & $\begin{array}{c}\text { Long. } \\
121^{\circ} 42^{\prime} \mathrm{E}\end{array}$ & Co. & No & $\begin{array}{c}\text { Lat. } \\
38^{\circ} 14^{\prime} \mathrm{N}\end{array}$ & $\begin{array}{c}\text { Long. } \\
121^{\circ} 42^{\prime} \mathrm{E}\end{array}$ & Co. \\
\hline 1 & 12.6 & 26.4 & 5 & 18 & 21.61 & 17.4 & 321 \\
\hline 2 & 13.8 & 26.41 & 1 & 19 & 22.2 & 16.2 & 318 \\
\hline 3 & 14.4 & 25.8 & 0 & 20 & 23.4 & 14.4 & 314 \\
\hline 4 & 15 & 25.81 & 359 & 21 & 24 & 12 & 309 \\
\hline 5 & 15.6 & 25.82 & 357 & 22 & 24.6 & 11.2 & 307 \\
\hline 6 & 16.2 & 25.23 & 355 & 23 & 24.61 & 10.8 & 304 \\
\hline 7 & 16.8 & 24.6 & 352 & 24 & 24.62 & 10.2 & 301 \\
\hline 8 & 17.4 & 24.61 & 351 & 25 & 24.63 & 9.6 & 300 \\
\hline 9 & 18 & 24 & 347 & 26 & 24.64 & 9 & 296 \\
\hline 10 & 18 & 23.4 & 347 & 27 & 24.65 & 8.4 & 293 \\
\hline 11 & 19.2 & 22.21 & 346 & 28 & 24.66 & 7.8 & 291 \\
\hline 12 & 19.21 & 22.2 & 341 & 29 & 24.65 & 7.2 & 288 \\
\hline 13 & 19.8 & 21.6 & 340 & 30 & 24.64 & 6.6 & 283 \\
\hline 14 & 19.81 & 21 & 336 & 31 & 24.64 & 6 & 282 \\
\hline
\end{tabular}

\begin{tabular}{|c|c|c|c||c|c|c|c|}
\hline 15 & 20.4 & 19.8 & 332 & 32 & 24.63 & 4.8 & 279 \\
\hline 16 & 21 & 19.2 & 327 & 33 & 24.01 & 3 & 274 \\
\hline 17 & 21.6 & 18 & 323 & 34 & 24.02 & 1.6 & 271 \\
\hline
\end{tabular}

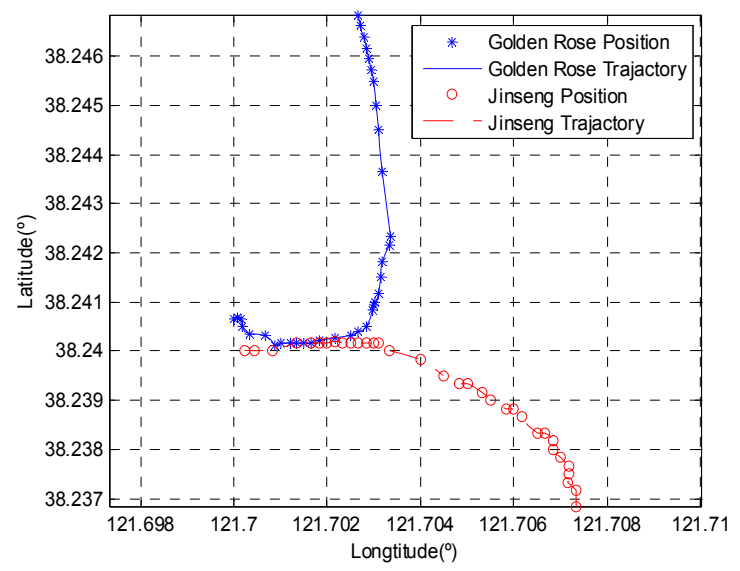

Figure 6. Trajectory simulation of ships in collision.

We used the curvature equation to calculate the interpolated trajectory and simulated the result of the curvature value. Result of Golden Rose and Jin-castle curvature are shown in figure 7-8.

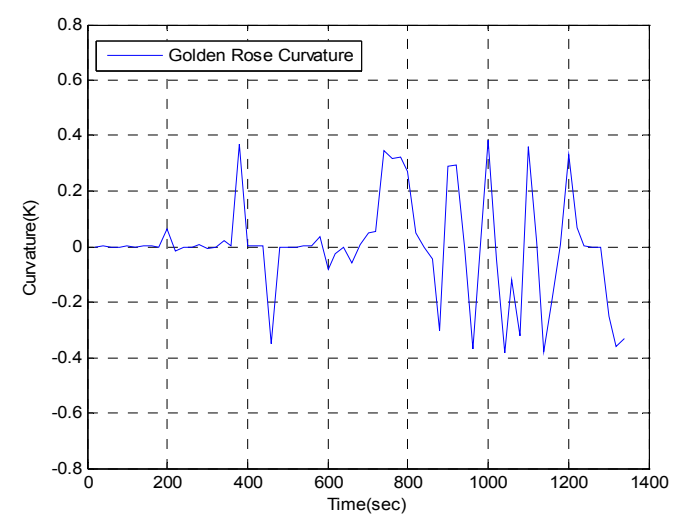

Figure 7. The change of the curvature for Golden Rose ship.

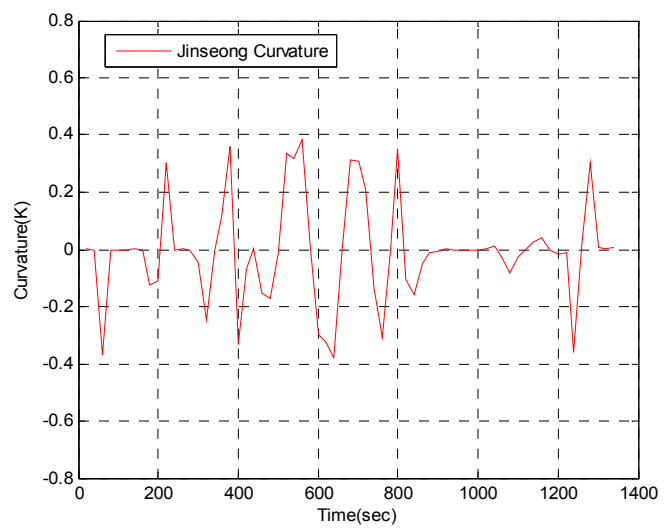

Figure 8 . The change of the curvature for Jinseong ship. 
Golden Rose and Jinseong hastily were turning for collision avoidance when collision was imminent. When Golden Rose turned to the right-hand side and Jinseong turned to the left-hand side, curvature values fluctuate greatly. The maximum value of the curvature of Golden Rose are $(+) 0.38,(-) 0.38$ and the maximum value of the curvature of Jinseong are (+)0.38, (-)0.37. In case of Jinseong, the curvature was higher than normal value due to movement fluctuate in straight route before turn left side.

\section{Conclusion}

The effective management of ship movements in a waterway is essential to reduce the rate of maritime accidents. The reason is that a lot of marine accidents by the human factor like the carelessness of navigator. The abnormal sailing ship having potential high risk may threaten normal voyage vessels on route.

In this research, the static and dynamic information of AIS data are collected and the curvature of ship trajectory is surveyed. Monte Carlo simulation was carried out to find out the characteristic of ship movement in a straight fairway. Through the simulations, we find the ship with large curvature which has irregularity of the ship movement. We know that the curvature can be used to recognize the characteristics of ship movement in a fairway.

This research proposes a simple algorithm of recognizing the potentially risky ships by observing their trajectories on the fairway. The proposed algorithm finds out the irregularity of ship movement. We calculate curvature from ship trajectory.

The algorithm effectively monitors the change of navigation pattern from the curvature analysis. If the system notices the irregularity of ship movement and warns to the navigator, it will contribute to the improvement of vessel safety on fairway. Our method improves VTS functions in an intelligent way by analyzing the navigation pattern of vessels under way.

\section{Acknowledgement}

This research was a part of the project titled "Development of the Intelligent Technology for Marine Accident Protection \& Salvage" funded by the Ministry of Land, Transport and maritime Affairs, Korea.

\section{References}

[1] J. S. Jeong, K.I Kim, and G. K. Park, "Maritime Traffic Characteristics in Waterway with Time Variant CPA," Proc. of European Navigation Conference 2012, Gdansk, Poland, April 2012.
[2] A. K. Debnath, H. C. Chin, and Md. M. Haque, "Modeling Port Water Collision Risk Using Traffic Conflicts," The Journal of Navigation, vol. 64, no. 4, pp.645-655, 2011.

[3] IMO Report of the Working Group, "Development of an ENavigation Strategy Implementation Plan," NAV56 /WP.5/Rev.1, 28 July 2010, pp. 1-65, 2010.

[4] K. G. Aarsæther and T. Moan, "Estimating Navigation Patterns from AIS," The Journal of Navigation, vol. 62, no. 4, pp.587-607, 2009.

[5] M.-C. Tsou, "Discovering Knowledge from AIS Database for Application in VTS", The Journal of Navigation, vol. 63, no. 3, pp.449-469, 2010.

[6] D. Y. Kim, G. K. Park, J. Jeong, and G. U. Kim, "Implementation of an Intelligent System for Identifying Abnormal Navigating Ships," International Journal of Fuzzy Logic and Intelligent Systems, vol.22, vo.1, pp.75-80, 2012.

[7] S. J. Lee and I. H. Park, "Database Design and Implementation for Vessel AIS Information Application," Journal of Navigation and Port Research, vol. 34, no. 5, pp. 343-348, 2010.

[8] IEC, IEC61993-2, "Annex B: New sentences due to AIS," Int. Elec. Committee, 2001.

\section{Eun Kyung Kim}

Graduation student of International Mokpo Maritime University

Research Area : Fuzzy, Marine safety system, Maritime transportation system etc.

E-mail : homki@mmu.ac.kr

\section{Jung Sik Jeong}

Professor of International Mokpo Maritime University

Research Area : Maritime transportation system, ship collision avoidance, Ship collision avoidance etc.

E-mail : jsjeong@mmu.ac.kr

\section{Gyei-Kark Park}

Professor of International Mokpo Maritime University Research Area : Fuzzy, Game theory, International logistic etc. E-mail : gkpark@mmu.ac.kr

\section{Nam Kyun Im}

Professor of International Mokpo Maritime University Research Area : Fuzzy, ANN, Marine safety system etc. E-mail : namkyun.im@mmu.ac.kr 